\title{
Risk Factors and Predictors of Refractory Childhood Epilepsy: Case Control Study
}

\author{
TAGHREED A.M. ISMAIL, M.D.*; MOHAMMED SALAH EL-DEEN, M.Sc.**; \\ EMAD EL-DEEN M. HAMMAD, M.D.** and KOTB A. METWALLY, M.D.** \\ The Departments of Public Health \& Community Medicine* and Pediatrics**, Faculty of Medicine, Assiut University
}

\begin{abstract}
Background: Each year, 3.5 million new cases of epilepsy are reported. Unfortunately, 6-14\% of these children will develop refractory epilepsy.

Aim: Is to determine the risk factors and predictors of refractory epilepsy.

Patients and Methods: Case control study was conducted at Assiut university children hospital. Cases were children aged 2-18 years who were diagnosed as refractory epilepsy whereas controls were matched to cases regarding age, sex, and they were diagnosed as responsive epilepsy.
\end{abstract}

Results: History of birth hypoxia, neonatal cyanosis, neonatal convulsions and NICU admission were significantly higher among patients with refractory epilepsy than those with responsive epilepsy. Past history of CNS infections, intracranial hemorrhage and febrile convulsions were significantly higher among patients with refractory epilepsy than those with responsive epilepsy. Physical and mental developmental delay occurred among $(80.6 \% \& 78.5 \%)$ of children with refractory epilepsy versus $(19.4 \% \& 18.3 \%)$ of children with responsive epilepsy with statistical significant difference. Age of seizure onset less than one year was reported among $75.3 \%$ of refractory epilepsy group versus $43 \%$ of those with responsive epilepsy. Multiple seizures type was reported among $36.5 \%$ of children with refractory epilepsy versus $6.5 \%$ of the responsive group. Moreover, about $90 \%$ of children with refractory epilepsy reported daily seizures at the disease onset. History of status epilepticus and presence of epileptic syndromes reported among $43 \% \& 26.9 \%$ respectively of children with refractory epilepsy, with statistical significant difference. Microcephaly, motor deficit were statistically higher among patients with refractory epilepsy than those with responsive epilepsy.

Conclusion: The most important independent predictors of refractoriness were: High initial seizures frequency, motor deficit, birth hypoxia, delayed mental development and febrile convulsions.

Recommendations: Good training of health care providers for the proper management of labor to avoid perinatal hypoxia, professional follow-up of children for early signs of develop-

Correspondence to: Dr. Taghreed A. M. Ismail

The Departments of Public Health \& Community Medicine Faculty of Medicine, Assiut University mental delay and health education and training to the caregiver and health care provider about proper management of fever to avoid febrile convulsions.

Key Words: Refractory epilepsy - Childhood epilepsy - Risk factors - Predictors.

\section{Introduction}

EPILEPSY is one of the most common childhood neurological illnesses. All over the world, approximately 10.5 million children are diagnosed with active epilepsy. Each year, 3.5 million new cases of epilepsy are reported. Forty percent of them are less than 18 years at time of diagnosis, and more than $80 \%$ of them live in developing countries [1]

Unfortunately, 6-14\% of these children will develop refractory epilepsy (RE). They will not respond well to antiepileptic drugs, and will continue to manifest seizures [2].

$\mathrm{RE}$ is a serious condition in children, leading to significant impairment in the quality of life, as well as behavioral and psychiatric problems including depression, sleep disorders, mood disorders, cognitive delay and poor scholastic performance. Most patients become severely emotionally affected, and coping with this chronic handicap may pose a burden on the family as well as on social, educational, and health services [3]. We suggest that medical refractory epilepsy in childhood can be predicted by monitoring risk factors. Along with early prediction, alternative therapies may be designed to provide better seizure control and quality of life for patients.

\section{Study questions:}

What are the risk factors for refractoriness among children with epilepsy? 
What are the predictors for refractoriness among children with epilepsy?

Aim of the study: Is to determine risk factors and predictors of refractory epilepsy among children attending Assiut University Children Hospital.

\section{Patients and Methods}

Study design: Case control study pital.

Study setting: Assiut University children hos-

Study period: April 2016 to March 2017.

\section{Study population:}

Cases: Children aged 2-18 years old, attended the pediatric neurology clinics or admitted at Assiut university children hospital and were diagnosed with refractory epilepsy according to Berg et al., [4].

Definition of refractory epilepsy: Inadequate seizure control despite appropriate medical therapy with at least two antiepileptic drugs at maximally tolerated doses for more than 18 months, or adequate seizure control with unacceptable drugrelated side effects [4].

Exclusion criteria: Patient proved to have different causes of convulsions as hypoglycaemia and hypocalcaemia, inappropriate anti-epileptic drug to the type of seizures, inappropriate doses of the drugs or poor patient's compliance to the treatment.

Controls were matched to cases regarding age, sex, and were diagnosed as having responsive epilepsy (didn't have any seizures of any type for a minimum of one year) from those attending the neurology outpatient clinics of Assiut University Children Hospital.

\section{Technical design:}

1- Data collection was done using semi-structured questionnaire through personal interview of the patient and caregivers. data collected included:

- Sociodemographic variables e.g. age, sex.

- Medical history: age at onset of seizures, seizure type, initial seizure frequency.

- Past medical history: Intracranial hemorrhage, CNS infections, status epilepticus, febrile and neonatal seizures and specific epileptic syndromes.

- Family history of parenteral consanguinity.

- History of perinatal insult: Birth hypoxia, neonatal cyanosis, neonatal jaundice, Neonatal convulsions, NICU admission.
- Developmental delay: Mental and/or physical.

- Treatment history: Type, number, dose and compliance to AEDs.

- Investigation results: Electroencephalogram abnormalities, neuroimaging findings.

2- General and full neurological examination were done for both cases and controls.

3- Investigations: Laboratory investigations (CA, $\mathrm{Mg}$ and Blood glucose) were done to exclude other causes of convulsions. Both cases and controls were confirmed to be epileptic by using EEG, EEG with provocations, repeated EEGs and in some doubtful cases, EEG video monitoring was done and neuroimaging (CT and/or MRI).

- Pilot study was done on 5 cases and 5 controls to test the questionnaire for any required rewording/rephrasing of sentences and assess the required time for completing the questionnaire and examination of the patients. The total required time was about 25-35 minutes for each patient.

Statistical analysis:

Data were entered, cleaned and recoded using the Statistical Package for Social Science (SPSS Inc., Chicago, IL, USA) version 20.

\section{- Data analysis.}

- Univariate analysis:Descriptive statistics (frequency \& percent for qualitative data, mean \pm SD for quantitative data).

- Bivariate analysis: Chi-square test $\left(\chi^{2}\right) /$ Fisher's Exact test were used to test the difference between the proportions of qualitative variables.

- Odds ratio was calculated for significant risk factors.

- Binary logistic regression analysis was done to determine the independent risk factors for development of refractory epilepsy.

- Statistical significance level was considered when $p<0.05$ for all statistical tests.

\section{Ethical considerations:}

- Study proposal was reviewed and approved by the ethical committee, faculty of medicine, Assiut University.

- Informed consent was obtained from the caregivers who were willing to participate in the study after explaining the study objectives to them. 
- Confidentiality of all data and privacy of the patients during examination were assured.

- All required investigations and management of cases were completed to the patients with referral to neuropediatric consultant if indicated.

\section{Acknowledgment:}

The researchers would like to acknowledge all patients and their caregivers who participated in the study.

\section{- Funding sources: None.}

- Conflicts of interest: None.

\section{Results}

In the present study, 93 cases and 93 controls were included. Males represented $63.4 \%$ of each group versus $36.6 \%$ for females. The mean age by years was $5.7 \pm 3.0$ for refractory group and $5.4 \pm 2.9$ for the responsive group.
Table (1) shows that history of birth hypoxia, neonatal cyanosis, neonatal convulsions and NICU admission were significantly higher among patients with refractory epilepsy than those with responsive epilepsy (OR was 3.0, 2.9,8.8 and 2.8 respectively). History of neonatal jaundice showed no statistical significant difference between both groups.

Table (2) shows that physical and mental developmental delay occurred among $80.6 \% \& 78.5 \%$ of children with refractory epilepsy versus $19.4 \%$ $\& 18.3 \%$ respectively of children with responsive epilepsy with statistical significant difference (OR $17.4 \& 16.3$ respectively).

Table (3) shows that past history of CNS infections, intracranial hemorrhage and febrile convulsions were significantly higher among patients with refractory epilepsy than those with responsive epilepsy (OR 7.4, 7.5 and 3.7 respectively). Positive family history of epilepsy showed no statistical significant difference between both groups.

Table (1): Distribution of children with refractory and responsive epilepsy according to neonatal history.

\begin{tabular}{|c|c|c|c|c|c|c|c|}
\hline \multirow[t]{2}{*}{ Variable } & \multicolumn{2}{|c|}{$\begin{array}{l}\text { Refractory } \\
\text { epilepsy }\end{array}$} & \multicolumn{2}{|c|}{$\begin{array}{l}\text { Responsive } \\
\text { epilepsy }\end{array}$} & \multirow{2}{*}{$\begin{array}{l}\text { Statistical } \\
\text { test }\end{array}$} & \multirow[t]{2}{*}{$p$-value } & \multirow[t]{2}{*}{ Odds ratio } \\
\hline & No. (93) & $\%$ & No. (93) & $\%$ & & & \\
\hline \multicolumn{8}{|c|}{ Birth hypoxia: } \\
\hline Yes & 32 & 34.4 & 14 & 15.1 & $x^{2}=9.4$ & 0.002 & 3.0 \\
\hline No & 61 & 65.6 & 79 & 84.9 & & & \\
\hline \multicolumn{8}{|c|}{ Neonatal cyanosis: } \\
\hline Yes & 30 & 32.3 & 13 & 14.0 & $x^{2}=8.7$ & 0.003 & 2.9 \\
\hline No & 63 & 67.7 & 80 & 86.0 & & & \\
\hline \multicolumn{8}{|c|}{ Neonatal jaundice: } \\
\hline Yes & 36 & 38.7 & 39 & 41.9 & $x^{2}=0.2$ & NS & \\
\hline No & 57 & 61.3 & 54 & 58.1 & & & \\
\hline \multicolumn{8}{|c|}{ Neonatal convulsions: } \\
\hline Yes & 15 & 16.1 & 2 & 2.2 & $x^{2}=10.9$ & 0.001 & 8.8 \\
\hline No & 78 & 83.9 & 91 & 97.8 & & & \\
\hline \multicolumn{8}{|c|}{ NICU admission: } \\
\hline Yes & 37 & 39.8 & 18 & 19.4 & $x^{2}=9.3$ & 0.002 & 2.8 \\
\hline No & 56 & 60.2 & 75 & 80.6 & & & \\
\hline
\end{tabular}

Table (2): Distribution of children with refractory and responsive epilepsy according to developmental history.

\begin{tabular}{lccccccc}
\hline Variable & \multicolumn{2}{c}{$\begin{array}{c}\text { Refractory } \\
\text { epilepsy }\end{array}$} & \multicolumn{2}{c}{$\begin{array}{c}\text { Responsive } \\
\text { epilepsy }\end{array}$} & Statistical \\
test & $p$-value & Odds ratio \\
\cline { 2 - 5 } & No. (93) & $\%$ & No. (93) & $\%$ & & \\
\hline Physical development: & 75 & 80.6 & 18 & 19.4 & $\mathrm{x}^{2}=69.9$ & $<0.0001$ & 17.4 \\
$\quad$ Delayed & 18 & 19.4 & 75 & 80.6 & & & \\
Appropriate to age & & & & & & & \\
Mental development: & 73 & 78.5 & 17 & 18.3 & $\mathrm{x}^{2}=67.5$ & $<0.0001$ & 16.3 \\
$\quad$ Delayed & 20 & 21.5 & 76 & 81.7 & & & \\
Appropriate to age & & & & & & & \\
\hline
\end{tabular}


Table (3): Distribution of children with refractory and responsive epilepsy according to past medical history.

\begin{tabular}{|c|c|c|c|c|c|c|c|}
\hline \multirow{2}{*}{ Variable } & \multicolumn{2}{|c|}{$\begin{array}{l}\text { Refractory } \\
\text { epilepsy }\end{array}$} & \multicolumn{2}{|c|}{$\begin{array}{l}\text { Responsive } \\
\text { epilepsy }\end{array}$} & \multirow{2}{*}{$\begin{array}{c}\text { Statistical } \\
\text { test }\end{array}$} & \multirow{2}{*}{$p$-value } & \multirow{2}{*}{ Odds ratio } \\
\hline & No. (93) & $\%$ & No. (93) & $\%$ & & & \\
\hline \multicolumn{8}{|c|}{ CNS infections: } \\
\hline Yes & 13 & 14.0 & 2 & 2.2 & Fisher's & 0.003 & 7.4 \\
\hline No & 80 & 86.0 & 91 & 97.8 & Exact & & \\
\hline \multicolumn{8}{|c|}{ Intracranial hemorrhage: } \\
\hline Yes & 7 & 7.5 & 1 & 1.1 & Fisher's & 0.03 & 7.5 \\
\hline No & 86 & 92.5 & 92 & 98.9 & Exact & & \\
\hline \multicolumn{8}{|c|}{ Febrile convulsions: } \\
\hline Yes & 52 & 55.9 & 24 & 25.8 & $x^{2}=17.4$ & $<0.0001$ & 3.7 \\
\hline No & 41 & 44.1 & 69 & 74.2 & & & \\
\hline \multicolumn{8}{|c|}{ Family history of epilepsy } \\
\hline Yes & 37 & 39.8 & 33 & 35.5 & $x^{2}=0.4$ & Ns & \\
\hline No & 56 & 60.2 & 60 & 64.5 & & & \\
\hline
\end{tabular}

Table (4) shows that age at seizure onset less than one year was reported among three quarters (75.3\%) of children with refractory epilepsy versus $43.0 \%$ of those with responsive epilepsy. Multiple seizures type was reported among $36.5 \%$ of children with refractory epilepsy versus $6.5 \%$ of the responsive group $(\mathrm{OR}=9.5)$. Moreover, about $90 \%$ of children with refractory epilepsy reported daily seizures at the disease onset versus $28.0 \%$ of the responsive group (OR=24.1). History of status epilepticus and presence of epileptic syndrome reported among $43 \%$ \& $26.9 \%$ respectively of children with refractory epilepsy with statistical significant difference.

Table (4): Distribution of children with refractory and responsive epilepsy according to seizure related factors.

\begin{tabular}{|c|c|c|c|c|c|c|c|}
\hline \multirow{2}{*}{ Variable } & \multicolumn{2}{|c|}{$\begin{array}{l}\text { Refractory } \\
\text { epilepsy }\end{array}$} & \multicolumn{2}{|c|}{$\begin{array}{l}\text { Responsive } \\
\text { epilepsy }\end{array}$} & \multirow{2}{*}{$\begin{array}{l}\text { Statistical } \\
\text { test }\end{array}$} & \multirow{2}{*}{$p$-value } & \multirow{2}{*}{ Odds ratio } \\
\hline & No. (93) & $\%$ & No. (93) & $\%$ & & & \\
\hline \multicolumn{8}{|l|}{ Age at onset: } \\
\hline$\leq$ One year & 70 & 75.3 & 40 & 43.0 & $x^{2}=20$ & $<0.0001$ & 4.0 \\
\hline$>$ One year & 23 & 24.7 & 53 & 57.0 & & & \\
\hline \multicolumn{8}{|l|}{ Type of convulsions: } \\
\hline Partial & 13 & 14.0 & 10 & 10.8 & $x^{2}=2.9$ & NS & Reference \\
\hline Generalized & 46 & 49.5 & 77 & 82.8 & & & 9.5 \\
\hline Multiple seizures & 34 & 36.5 & 6 & 6.5 & $x^{2}=27.4$ & 0.01 & \\
\hline \multicolumn{8}{|c|}{ Initial convulsions frequency: } \\
\hline Daily & 84 & 90.3 & 26 & 28.0 & $x^{2}=74.9$ & $<0.0001$ & 24.1 \\
\hline less frequent & 9 & 9.7 & 67 & 72.0 & & & \\
\hline \multicolumn{8}{|c|}{ History of status epilepticus: } \\
\hline Yes & 40 & 43.0 & 7 & 7.5 & $x^{2}=31$ & $<0.0001$ & 9.3 \\
\hline No & 53 & 57.0 & 86 & 92.5 & & & \\
\hline \multicolumn{8}{|l|}{ Epileptic syndrome: } \\
\hline Yes & 25 & 26.9 & 12 & 12.9 & $x^{2}=5.7$ & 0.02 & 2.5 \\
\hline No & 68 & 73.1 & 81 & 87.1 & & & \\
\hline
\end{tabular}


Fig. (1) shows that the reported epileptic syndromes in refractory epilepsy group were west syndrome (56.0\%), Lennox-gaustaut syndrome $(40.0 \%)$ and autosomal dominant nocturnal frontal lobe epilepsy $(4.0 \%)$ whereas the epileptic syndromes in responsive epilepsy group were benign rolanding epilepsy (83.4\%) and benign occipital lobe epilepsy of childhood (16.6\%).

Table (5) shows that microcephaly, abnormal cranial nerves examination, motor deficit and presence of associated comorbidity were significantly higher among patients with refractory epilepsy (OR was 9.0, 11.6, 21.3 and 6.1 respectively).

Neither dysmorphic features, congenital malformation or macrocephaly showed any statistical significant difference between both groups.
Table (6) shows that the most common reported abnormalities among children with refractory epilepsy were multifocal and focal abnormalities (40.8\% \& $24.7 \%$ respectively) whereas the most common reported abnormalities among children with responsive epilepsy were focal then multifocal abnormalities (69.9\% \& $23.7 \%$ respectively).

Fig. (2) shows that presence neuroimaging abnormality was significantly higher among patients with refractory epilepsy than those with responsive epilepsy $(75.3 \%$ versus $23.7 \%$ respectively), OR was 9.8 .

Table (7) binary logistic regression analysis revealed that the most important independent predictors of refractoriness were: High initial seizures frequency, presence of motor deficit, birth hypoxia, delayed mental development and history of febrile convulsions.

Table (5): Clinical examination of children with refractory and responsive epilepsy.

\begin{tabular}{|c|c|c|c|c|c|c|c|}
\hline \multirow{2}{*}{ Variable } & \multicolumn{2}{|c|}{$\begin{array}{l}\text { Refractory } \\
\text { epilepsy }\end{array}$} & \multicolumn{2}{|c|}{$\begin{array}{c}\text { Responsive } \\
\text { 2tepitepiys }\end{array}$} & \multirow{2}{*}{$i<\underset{\text { test }}{a} 1$} & \multirow{2}{*}{$p$-value } & \multirow{2}{*}{ Odds ratio } \\
\hline & No. (93) & $\%$ & No. (93) & $\%$ & & & \\
\hline \multicolumn{8}{|c|}{ Dysmorphic features: } \\
\hline Yes & 5 & 5.4 & 3 & 3.2 & Fisher's Exact & Ns & \\
\hline No & 88 & 94.6 & 90 & 96.8 & test & & \\
\hline \multicolumn{8}{|c|}{ Head circumference: } \\
\hline Normal & 62 & 66.7 & 84 & 90.3 & $\mathrm{X}^{2}=15.8$ & $<0.0001$ & Reference \\
\hline Microcephaly & 20 & 21.5 & 3 & 3.2 & & & \\
\hline Macrocephaly & 11 & 11.8 & 6 & 6.5 & $X^{2}=3.1$ & Ns & 9.0 \\
\hline \multicolumn{8}{|c|}{ Congenital malformation: } \\
\hline Yes & 7 & 7.5 & 3 & 3.2 & Fisher's Exact & Ns & \\
\hline No & 86 & 92.5 & 90 & 96.8 & test & & \\
\hline \multicolumn{8}{|c|}{ Neuro cutaneous syndrome: } \\
\hline Yes & $5^{*}$ & 5.4 & 0 & 0 & - & - & - \\
\hline No & 88 & 94.6 & 93 & 100 & & & \\
\hline \multicolumn{8}{|c|}{ Cranial nerve examination: } \\
\hline Abnormal & 26 & 28.0 & 3 & 3.2 & $x^{2}=21.6$ & $<0.0001$ & 11.6 \\
\hline Normal & 67 & 72.0 & 90 & 96.8 & & & \\
\hline \multicolumn{8}{|l|}{ Motor deficit: } \\
\hline Yes & 62 & 66.7 & 8 & 8.6 & $x^{2}=66.8$ & $<0.0001$ & 21.3 \\
\hline No & 31 & 33.3 & 85 & 91.4 & & & \\
\hline \multicolumn{8}{|c|}{ Associated comorbidity: } \\
\hline Yes & 50 & 53.8 & 15 & 16.1 & $x^{2}=29$ & $<0.0001$ & 6.1 \\
\hline No & 43 & 46.2 & 78 & 83.9 & & & \\
\hline
\end{tabular}

*The reported five cases of neuro-cutaneous syndromes were three cases were tuberous sclerosis and other two cases were sturge weber syndrome. 
Table (6): EEG abnormalities among children with refractory and responsive epilepsy.

\begin{tabular}{lcccc}
\hline \multirow{2}{*}{$\begin{array}{l}\text { EEG } \\
\text { abnormality }\end{array}$} & \multicolumn{2}{c}{$\begin{array}{c}\text { Refractory } \\
\text { epilepsy }\end{array}$} & \multicolumn{2}{c}{$\begin{array}{c}\text { Responsive } \\
\text { epilepsy }\end{array}$} \\
\cline { 2 - 5 } & No. (93) & $\%$ & No. (93) & $\%$ \\
\hline Focal & 23 & 24.7 & 65 & 69.9 \\
Multifocal & 38 & 40.8 & 22 & 23.7 \\
Generalized & 16 & 17.3 & 3 & 3.2 \\
3HZ/second & 2 & 2.1 & 3 & 3.2 \\
Hypsaarrhythmia & 14 & 15.1 & 0 & 0.0 \\
\hline
\end{tabular}

Table (7): Binary logistic regression analysis of factors associated with refractory epilepsy.

\begin{tabular}{lcc}
\hline Variable & $p$-value & Odds ratio \\
\hline High initial seizure frequency & 0.0001 & 21.7 \\
Presence of motor deficit & 0.001 & 6.4 \\
Birth hypoxia & 0.008 & 5.6 \\
Delayed mental development & 0.003 & 4.5 \\
Febrile convulsions & 0.03 & 3.1 \\
\hline
\end{tabular}
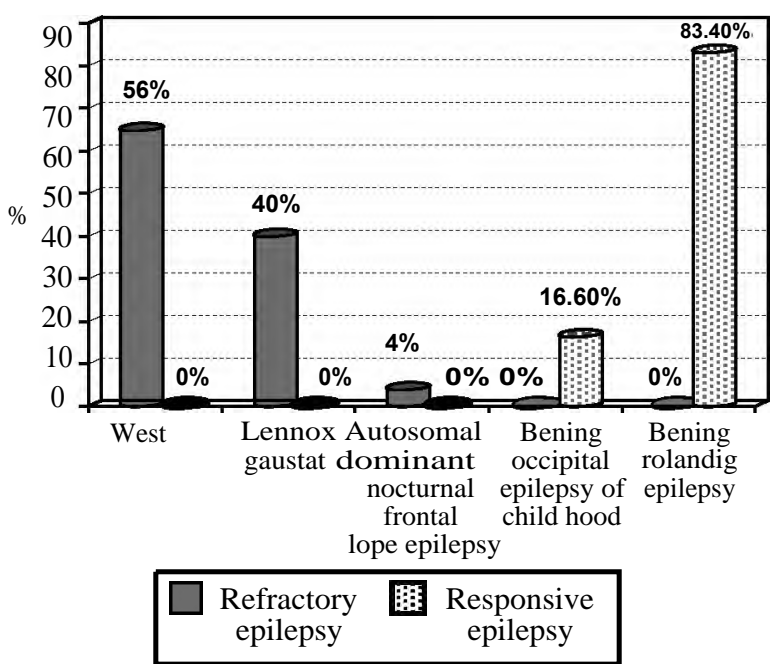

Fig. (1): Type of epileptic syndrome among children with refractory and responsive epilepsy

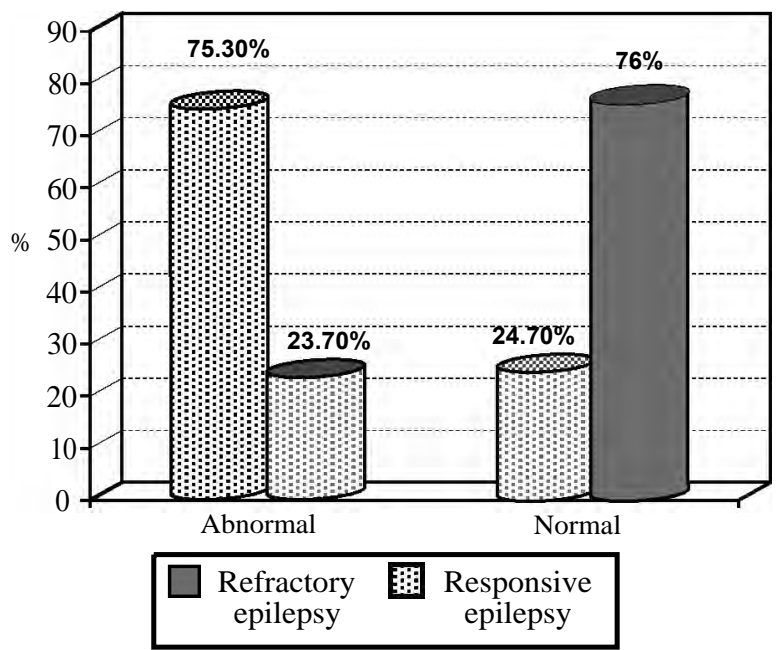

Fig. (2): Distribution of children with refractory epilepsy according to Neuroimaging abnormalities.

\section{Discussion}

In the present study birth hypoxia and history of neonatal cyanosis were significantly higher among refractory epilepsy group than the responsive group. Those findings are with concordance to Chawla et al., [5] who reported that perinatal asphyxia was the main cause of symptomatic epilepsy in intractable group. Moreover Moinuddin et al., [6] revealed that hypoxic-Ischaemic damage of the brain due to perinatal asphyxia and cerebral palsy were the main causes of symptomatic epilepsy and $87.5 \%$ of those children subsequently developed intractable epilepsy. Birth asphyxia is a concern for developing countries, where antenatal and perinatal care is still poor [6].

The present study revealed that neonatal convulsions were significantly higher among refractory epilepsy group than the responsive group. This finding is conformed to Chawla et al., [5] and Moinuddin et al., [6]. Moreover the present study revealed neonatal seizures as an important predictor of refractoriness, the same was reported by Berg et al., [4] and Ohtsuka et al., [7].

Neonatal seizures can be associated with strong epileptic foci induced by neuronal damage during this period of rapid brain development. Furthermore, most of these children demonstrate a history of perinatal asphyxia, congenital malformations, and other factors that play an important role in the development of refractory epilepsy [8] .

The present study revealed that delayed developmental milestones were significantly higher among patients with refractory epilepsy than those with responsive epilepsy. This result is in agreement with Patil et al., [9].

The association between the presence of developmental delay and poor outcome may represent widespread albeit subtle, cortical structural abnormalities. Such a theory may also underlies the large proportion of patients with associated co-morbid conditions [10].

Our study reported that history of intracranial haemorrhage and CNS infections (encephalitis/ meningitis) was statistically higher in refractory epilepsy group than in responsive group. This is in agreement with Kasprzyk et al., [11].

The present study reported that history of febrile convulsions was statistically higher among refractory epilepsy group than in the responsive group. This finding is confirmed to Tripathi et al., [10] 
On the other hand, Ohtsuka et al., [7] reported a lack of association between febrile seizures and refractory epilepsy. Moreover, Berg et al., [4] reported a slightly protective association between febrile seizures and intractability.

A positive family history was not a predictor of refractory epilepsy in the present study. This is in agreement with Patil et al., [9].

Indeed, positive family history is more commonly reported in benign conditions like idiopathic generalized tonic-clonic epilepsy [12]

In the present study, the early onset of seizures before the age of one year was statistically higher among refractory epilepsy group than the responsive group. This finding is conformed to Patil et al., [9]. Age at onset was among the most important predictors of intractable childhood epilepsy [5]

In our study, the multiple seizure types and partial seizures were statistically higher among refractory epilepsy group than the responsive group, while generalized seizures were higher among the responsive group. This observation is in agreement with Mattson et al., [13] . On the contrary, Sanyal et al., [14] reported that generalized seizures have the worst outcome whereas Chawla et al., [5] did not report seizure type as a predictor of intractability.

The present study reported that high initial seizure frequency was a significant risk factor of refractory epilepsy. This is in agreement with Chawla et al., [5].

High initial seizure frequency was a significant predictor of intractability in the present study. On the same line, Tripathi et al., [10] identified high initial seizure frequency as a significant prognostic factor.

Malignant syndromes of epilepsy which are difficult to control present with high frequency of seizure. Also frequent seizure itself further damages the developing brain which already had got pathology of seizure [6]

Our study also revealed that history of status epilepticus was statistically higher among refractory epilepsy group than the responsive group This finding is in agreement with Berg et al., [4] and Ohtsuka et al., [7]. On the other hand, Moinuddin et al., [15] concluded that history of status epilepticus was not revealed as a predictor of unfavorable outcome or intractability.
Less frequent status can be more devastating than frequent short episodes of seizure [15]. It has also been confirmed that a long-lasting persistence of epileptic seizures and occurrence of status epilepticus affects intellectual development [16]

In our study the presence of epileptic syndromes were statistically higher among refractory epilepsy group than the responsive group. This is conformed to Seker Yilmaz et al., [8] and Berg et al., [17].

In the present study microcephaly was statistically higher among refractory epilepsy group than the responsive group, this is in agreement with many other studies $[\mathbf{5 , 1 5 , 1 7 ]}$. Also, Datta and Wirrell [18] declared that epilepsy due to structural malformations as microcephaly is difficult to control.

The present study revealed that abnormal cranial nerve examination and motor deficit in the neurological examination were statistically higher among refractory epilepsy group than the responsive group. These findings are in agreement with many studies $[15,19]$.

Presence of underlying neurologic deficit points to either the intrinsic severity of epilepsy or to the severity of underlying etiology. These two factors may account for the revealed pharmaco-resistance [9]. Moreover, many well-known refractory epilepsy syndromes are characterized by neurologic deficit [19].

In our study we reported that the neuro-imaging abnormality was statistically higher among refractory group than the responsive group. Semah and Ryvlin [20] revealed that the presence of a brain lesion demonstrated by neuroimaging or suggested by a neurological deficit or a developmental delay are the main predictors of intractability of epilepsy.

Conclusion: The main predictors of development of refractory epilepsy were high initial seizures frequency, presence of motor deficit, birth hypoxia, delayed mental development and history of febrile convulsions.

\section{Recommendations:}

- Good training of health care providers for the proper management of labor to avoid perinatal hypoxia.

- Professional follow-up of children for early signs of developmental delay.

- Health education and training to the caregiver and health care provider about proper management of fever to avoid febrile convulsions. 


\section{References}

1- SEKER B., MD Y., OKUYAZ C. and KOMUR M.: Predictors of Intractable Childhood Epilepsy. Pediatr. Neurol., 48: 52-5. Available from: https://www.pedneur.com /article/S0887-8994(12)00445-6/pdf, 2013.

2- ARTS W.F.M., BROUWER O.F., PETERS A.C.B., STROINK H., PEETERS E.A.J, SCHMITZ P.I.M., et al.: Course and prognosis of childhood epilepsy: 5-year followup of the Dutch study of epilepsy in childhood. Brain., 127 (8): 1774-84. Available from: http://www.ncbi.nlm.nih. gov/pubmed/15201192, 2004.

3- GURURAJ A., SZTRIHA L., HERTECANT J. and EAPEN V.: Clinical predictors of intractable childhood epilepsy. J. Psychosom. Res., 61 (3): 343-7. Available from: http://www.ncbi.nlm.nih.gov/pubmed/16938512, 2006.

4- BERG A.T., SHINNAR S., LEVY S.R., TESTA F.M., SMITH-RAPAPORT S., BECKERMAN B., et al.: Twoyear remission and subsequent relapse in children with newly diagnosed epilepsy. Epilepsia., 42 (12): 1553-62. Available from: htp://www.ncbi.nlm.nih.gov/pubmed/ 11879366, 2001.

5- CHAWLA S., ANEJA S., KASHYAP R. and MALLIKA V.: Etiology and clinical predictors of intractable epilepsy. Pediatr. Neurol., 27 (3): 186-91. Available from: http://www.ncbi.nlm.nih.gov/pubmed/12393128, 2002.

6- MOINUDDIN A., RAHMAN M., AKHTER S. and KAWSER C.: Predictors of Childhood Intractable Epilepsy- A Retrospective Study in A Tertiary Care Hospital. Bangladesh J. Child. Heal., 33 (1): 6-15. Available from: http://www. banglajol.info/index.php/BJCH/article/ view/5669, 2010.

7- OHTSUKA Y., YOSHINAGA H. and KOBAYASHI K.: Refractory Childhood Epilepsy and Factors Related to Refractoriness. Epilepsia., 41 (s9): 14-7. Available from: http://doi.wiley.com/10.1111/i.1528-1157.2000.tb02212.x. 2000.

8- SEKER YILMAZ B., OKUYAZ C. and KOMUR M.: Predictors of Intractable Childhood Epilepsy. Pediatr Neurol 48 (1): 52-5. Available from: http://www.ncbi.nlm. nih.gov /pubmed/23290021, 2013.

9- PATIL M.G., MALIK S., JOSHI S. and GAJRE M.: Early Predictors of Intractable Childhood Epilepsy. Bombay Hospital Journal., 51 (1): 36-43, 2009.

10- TRIPATHI M., PADHY U.P., VIBHA D., BHATIA R., PADMA SRIVASTAVA M.V., SINGH M.B., et al.: Predictors of refractory epilepsy in North India: A casecontrol study. Seizure., 20 (10): 779-83. Available from:
htps://www.sciencedirect.com/science/article/pii/S 1059 $131111002020,2011$.

11- KASPRZYK M., BROLA W. and WENDORFF J.: Assessment of clinical risk factors for drug-resistant epilepsy in children and teenagers. Med. Stud., 3 (3): 141-7. Available from: http://www.termedia.pl/doi/ 10.5114/ms. 2014.45418. 2014.

12- FORFAR J.O., ARNEIL G.C., MCINTOSH N., HELMS P. and SMYTH R.L.: Forfar and Arneil's textbook of pediatrics. Churchill. Livingstone., 1985 p., 2003.

13- MATTSON R.H., CRAMER J.A. and COLLINS J.F.: Prognosis for total control of complex partial and secondarily generalized tonic clonic seizures. Department of Veterans Affairs Epilepsy Cooperative Studies No. 118 and No. 264 Group. Neurology., 47 (1): 68-76. Available from: http://www.ncbi.nlm.nih.gov/ pubmed/8710127, 1996.

14- SANYAL S.K., CHANDRA P.S., GUPTA S., TRIPATHI M., SINGH V.P., JAIN S., et al.: Memory and intelligence outcome following surgery for intractable temporal lobe epilepsy: Relationship to seizure outcome and evaluation using a customized neuropsychological battery. Epilepsy Behav., 6 (2): 147-55. Available from: htp://www.ncbi.nlm. nih.gov/pubmed/15710297, 2005.

15-MOINUDDIN A., RAHMAN M., AKHTER S. and KAWSER C.: Predictors of Childhood Intractable Epilepsy-A Retrospective Study in A Tertiary Care Hospital. Bangladesh J. Child. Heal., 33 (1): 6-15. Available from: htps:// www.banglajol.info/index.php/ BJCH/article/viewFile 15669/4435, 2009.

16- FASTENAU P.S., JOHNSON C.S., PERKINS S.M., BYARS A.W., DEGRAUW T.J., AUSTIN J.K, et al.: Neuropsychological status at seizure onset in children: risk factors for early cognitive deficits. Neurology., 73 (7): 526-34. Available from: htp://www.ncbi.nlm.nih. . gov/pubmed/19675309. 2009.

17- BERG A.T., LEVY S.R., NOVOTNY E.J. and SHINNAR S.: Predictors of Intractable Epilepsy in Childhood: A Case-Control Study. Epilepsia., 37 (1): 24-30. Available from: http://doi.wiley.com/10.1111/j.1528-, 1996.

19- MALIK M.A., HAMID M.H., AHMED T.M. and ALI Q.: Predictors of intractable childhood epilepsy. J. Coll. Physicians. Surg. Pak., 18 (3): 158-62. Available from: http://www.ncbi.nlm.nih.gov/pubmed/18460244 . 2008.

20- SEMAH F. and RYVLIN P.: Global care of patients with drug resistant epilepsy Can we predict refractory epilepsy at the time of diagnosis? Epileptic Disord 7 (1): 510-3. Available from: http://www.jle.com/download/epd-266 564-, 2005. 


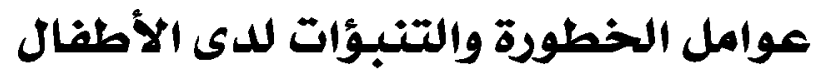

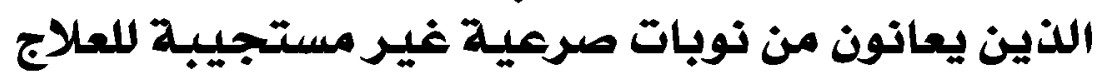

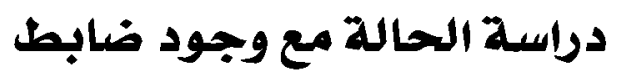

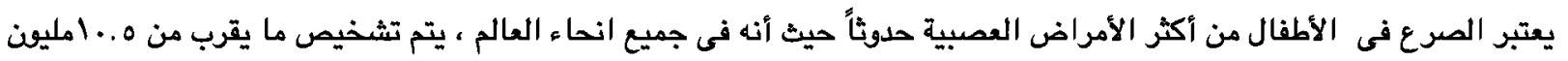

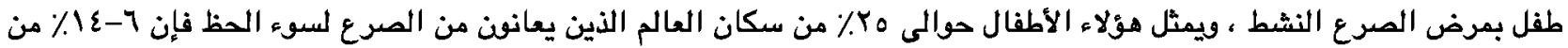

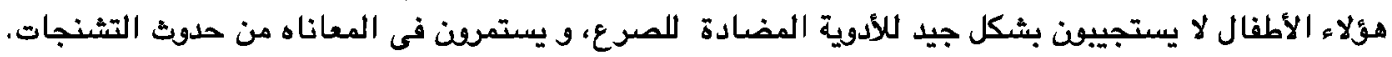

الهدف من الدراسة: تحديد عوامل الخطورة المرتبطة بحدوث الصرع الغير مستحيب اللعلاج وتحديد العوامل المرتبطة التى يمكن أن تساعد

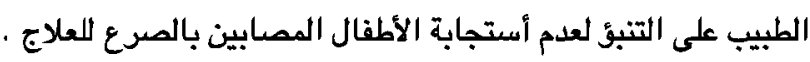

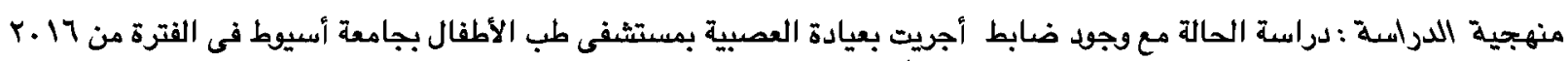

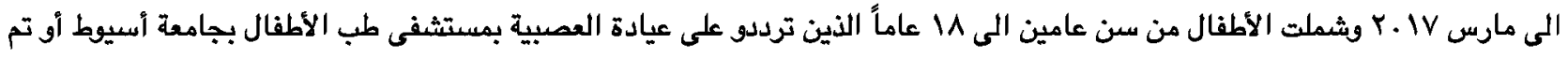
حجزمم بمستشفى طب الأطفال بجامعة أسيوط فى تلك الفال الفترة.

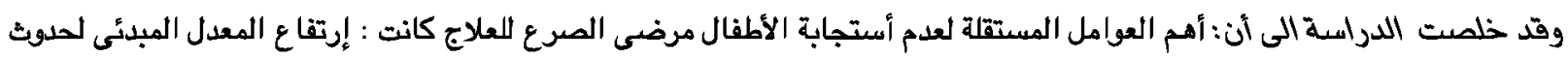

التشنجات والتشنجات الحرارية وتأخر النمو العقلى وتاريخ نقص الاكسجين أثناء الولادة و المتلازمات العات الجلدية العصبية. 